\title{
THE LINEAR RELATION OF CEREBRAL BLOOD FLOW TO ARTERIAL OXYGEN SATURATION IN HYPOXIC HYPOXIA INDUCED WITH NITROUS OXIDE OR NITROGEN
}

\author{
W.W. Stoyka, D.Z.N. Frankel, ANd J.C. Kay
}

THE RESPONSE of cerebral blood flow to hypoxia has been well documented in three animal studies by Kogure,' Johannsson ${ }^{2}$ and Gray, ${ }^{3}$ and in human subjects by Shimojyo ${ }^{4}$ and Shapiro. ${ }^{5}$ Oxygen exerts negligible effects on cerebral blood flow under normal oxygen tensions or moderate arterial hypoxia to arterial partial pressures $\left(\mathrm{Pa}_{\mathrm{O}_{2}}\right)$ of $60 \mathrm{~mm} \mathrm{Hg}(7.98 \mathrm{kPa})$. Neurophysiologists have had unsatisfactory results in attempts to relate the curvilinear hyperbolic relationship of cerebral blood flow and hypoxia to a mathematical equation. Shapiro has shown that the problem is further amplified by changes in arterial carbon dioxide $\left(\mathrm{PaCO}_{2}\right) .^{5}$

Respiratory physiologists such as Lloyd ${ }^{6}$ and Severinghaus $^{7}$ have documented that a similar curvilinear hyperbolic response occurs when ventilation is plotted against decreasing $\mathrm{Pa}_{\mathrm{O}_{2}}$. Mathematical manipulations to linearize this relationship proved as difficult as the cerebral blood flow versus hypoxia response. Recently Rebuck. et al. ${ }^{8}$ showed that ventilation was a linear function of oxygen saturation $\left(\mathrm{Sa}_{\mathrm{O}_{2}}\right)$ under isocapnic conditions. Assuming that a similar relationship may possibly exist for cerebral blood flow and $\mathrm{St}_{0_{2}}$, we undertook a study to clearly delineate the response of cerebral blood flow to hypoxia in dogs under normocapnic conditions with hypoxia associated with nitrous oxide or nitrogen.

\section{METHODS}

Anaesthesia was induced in 14 unpremedicated dogs with thiopentone $5 \mathrm{mg} / \mathrm{kg}$. The trachea was intubated and ketamine $2 \mathrm{mg} / \mathrm{kg}$ was used to maintain anaesthesia for normal cerebral blood flow, according to Dawson ${ }^{9}$ and two previous studies in our laboratory. ${ }^{10.11}$ Pancuronium bromide was introduced to produce muscle paralysis to allow artificial ventilation with stable $\mathrm{Pa}_{\mathrm{CO}_{2}}$ and maintenance of normal cardiac output

W. W. Stoyka, M.D., F.R.C.P.(C), Department of Anaesthesia, St. Michael's Hospital, and University of Toronto. D.Z.N. Frankel, M.D., Resident, Department of Anaesthesia. Univ. of Toronto. J.C. Kay, A.I.M.L.T., Technician, Department of Anaesthesia, St. Michael's Hospital, and University of Toronto. 474 and blood pressure. An OHIO 560 ventilator was preset for 21 per cent oxygen and adjusted to maintain $\mathrm{Pa}_{\mathrm{CO}_{2}}$ at $(40 \pm 3$ torr) $5.32 \pm 0.4 \mathrm{kPa}$. A Godart end-tidal infra-red analyzer facilitated maintenance of normal $\mathrm{Pa}_{\mathrm{CO}_{2}}$. The femoral artery was cannulated for determining arterial blood pressure, and to obtain samples for blood gas analysis and haematological data. The oxygen saturation and haemoglobin were measured with an Instrumentation Laboratories co-oximeter 182, while blood gases were measured with Radiometer electrodes for $\mathrm{pH}, \mathrm{Pa}_{2}$ and $\mathrm{Pa}_{\mathrm{CO}_{2}}$. The femoral vein was cannulated and a\#6F paediatric Swan Ganz thermodilution cardiac output catheter was inserted and passed through the heart to the pulmonary artery with the assistance of an Edwards venous pressure monitor. This catheter allowed for central venous pressure and cardiac output measurements when used in conjunction with an Edwards cardiac output computer model 9510.

Either the vertebral artery or the internal carotid artery was exposed surgically and a $16-$ gauge plastic cannula was inserted. A pursestring suture was placed to prevent leaking at the puncture site but allowing maintenance of free flow in the artery. This cannula was the injection site for 1 millicurie of xenon ${ }^{133}$ for cerebral blood flow measurement. A sagittal incision in skin over the skull allowed for stripping of the extracranial muscle from the skull to prevent intracranialextracranial contamination. After xenon injection, total cerebral blood flow was obtained by the initial slope technique, ${ }^{12}$ obtained by scintillation crystal counting of radioactive xenon emission with Nuclear Chicago equipment. Computer analysis enabled the rapid calculation of cerebral blood flow. Figure 1 illustrates the methodology used in this study.

Measurements were obtained at 21 per cent oxygen for cerebral blood flow, cardiac output, vascular parameters, acid base measurements and haematology. Hypoxia was produced by introduction to the inspired gas mixture of nitrous oxide $\left(\mathrm{N}_{2} \mathrm{O}\right)$ in seven animals and nitrogen $\left(\mathrm{N}_{2}\right)$ in seven animals. Inspired oxygen was decreased to $17,15,13,11,9$ and 7 per cent at 15-minute 


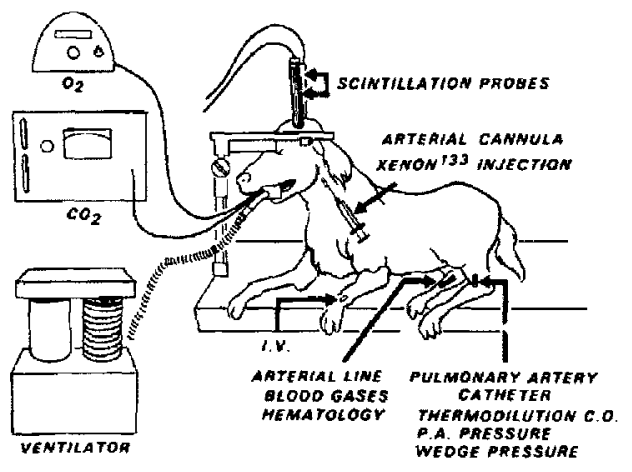

Figure 1. Diagrammatic representation of methodology.

intervals until termination of the experiment. Changes in inspired oxygen concentration were facilitated by the use of a Beckman oxygen analyzer. After each period of progressive hypoxia, all measurements were repeated. The data obtained were converted to percentage change. Computer graphing then enabled plotting of percentage change in cerebral blood flow against $\mathrm{Pa}_{0_{2}}$ and $\mathrm{Sa}_{0_{2}}$, to delineate the relationship of cerebral blood flow to hypoxia induced with nitrous oxide and with nitrogen.

\section{Results}

The response of cerebral blood flow to progressive hypoxia induced with nitrous oxide or nitrogen for the 14 animals in our study is shown in Figure 2. This plot of cerebral blood flow against $\mathrm{Pa}_{0_{2}}$ is recognized by neurophysiologists as the standard representation of this relation-

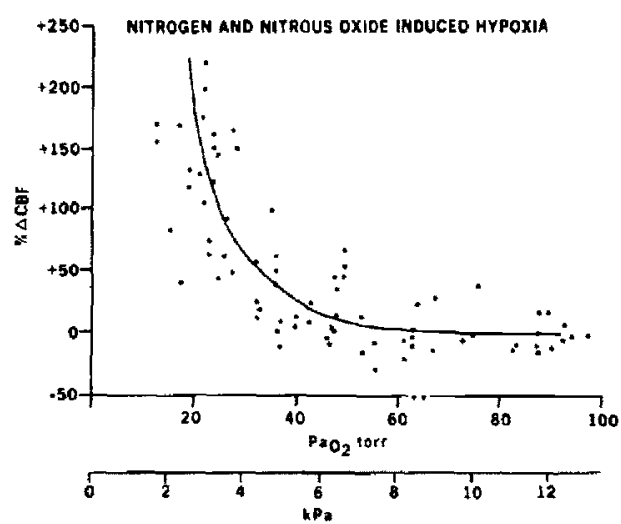

Figure 2. Response of cerebral blood flow to hypoxia induced with nitrogen or nitrous oxide in 14 dogs.

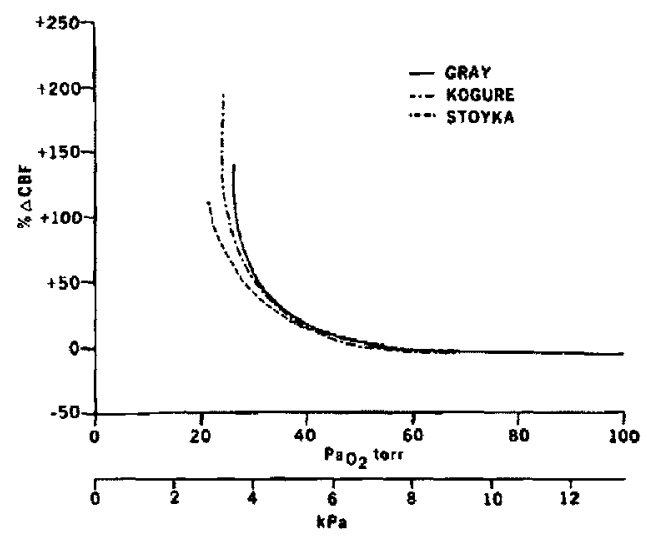

Figure 3. Comparison of cerebral blood flow response to hypoxia induced with nitrogen from the present study with studies by Gray, ef al. ${ }^{3}$ and Kogure, et al.'

ship. It is obvious that it would be difficult to convert this curvilinear relationship to a straight forward mathematical form or equation.

Figure 3 documents the response of cerebral blood flow to $\mathrm{Pa}_{\mathrm{O}_{2}}$ in nitrogen hypoxia in our study compared to results obtained with nitrogen by Kogure ${ }^{1}$ and Gray ${ }^{3}$ in dogs. A similar hypoxic response has also been shown by Johannsson ${ }^{2}$ in rats and Shapiros in man. The results of these other studies adds verification to the methodology used and the results obtained in our laboratory.

Utilizing the data from Figure 3 and the equations of Seringhaus ${ }^{13}$ and Kelman, ${ }^{14} \mathrm{~Pa}_{0_{2}}$ values were converted mathematically to $\mathrm{Sa}_{\mathrm{O}_{2}}$. This relationship of cerebral blood flow to calculated $\mathrm{Sa}_{\mathrm{O}_{2}}$ is not entirely accurate because it makes no allowances for actual changes in haemoglobin, acid-base status and oxyhaemoglobin dissociation. Figure 4 represents cerebral blood flow plotted against calculated $\mathrm{Sa}_{\mathrm{O}_{2}}$ for the work of Kogure, Gray and ourselves. Since little change in cerebral blood flow occurs as $\mathrm{Pa}_{\mathrm{O}_{2}}$ drops to 60 m m Hg ( $7.98 \mathrm{kPa})$, we have only included cerebral blood flow versus $\mathrm{Sa}_{\mathrm{O}_{2}}$ data in the hypoxic range. The striking feature in these studies is the obviously apparent and similar linear relationship of cerebral blood flow and calculated $\mathrm{Sa}_{\mathrm{O}_{2}}$.

The response of cerebral blood flow to actually measured $\mathrm{Sa}_{\mathrm{O}_{2}}$ in our study is shown in Figure 5. These changes occur concomitantly with changes in haemoglobin, acid base balance and oxyhaemoglobin dissociation curve. Three important features are apparent from these results. We believe that this is the first time that a linear relationship between cerebral blood flow and 


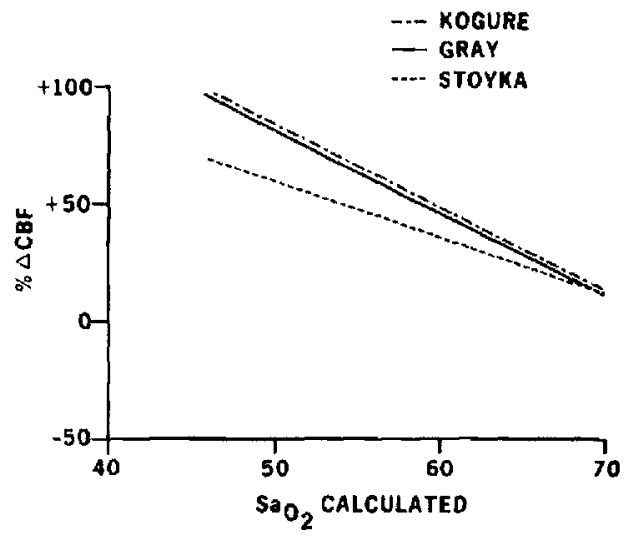

FICURE 4. The linear relationship of cerebral blood flow to calculated $\mathrm{Sa}_{\mathrm{O}_{2}}$ from this study and those of Gray, et al. ${ }^{3}$ and Kogure, et al. ${ }^{1}$

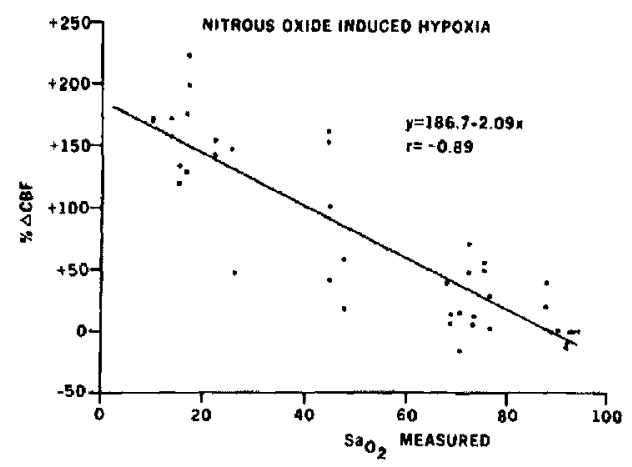

FIGURE 5. The linear relationship of cerebral blood fow to measured $\mathrm{Sa}_{\mathrm{O}_{2}}$.

measured $\mathrm{Sa}_{\mathrm{O}_{2}}$ has been documented. Secondly, for each one per cent change in $\mathrm{Sa}_{\mathrm{O}_{2}}$ the cerebral blood flow increase by 2.09 per cent as shown by the equation $y=186.7-2.09 x$. The third feature is the documented hypoxic response of seven animals specifically subjected to hypoxia induced with nitrous oxide.

The responses of cerebral blood flow to hypoxia induced with nitrous oxide and with nitrogen are compared in Figure 6. The impressive feature is the increase in cerebral blood flow in hypoxia induced with nitrous oxide, where hypoxia produced a 2.09 per cent increase in cerebral blood flow compared to 1.02 per cent for nitrogen hypoxia for each one per cent decrease in oxygen saturation. This adds confirmation to the work of Theye ${ }^{15}$ and Sakabe ${ }^{16}$ in dogs and Sakabe ${ }^{17}$ in humans showing that nitrous oxide causes significant increases in cerebral blood

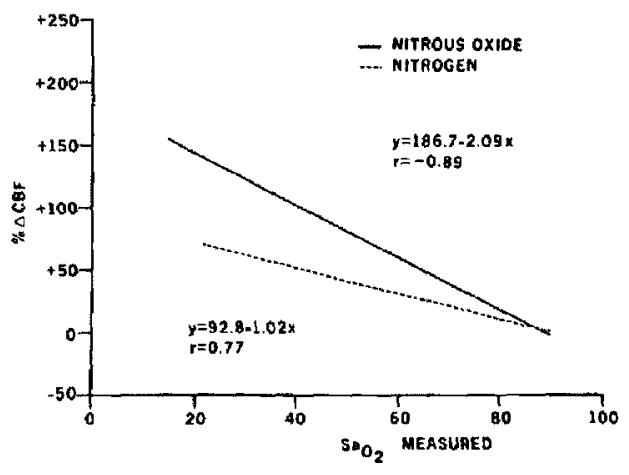

Figure 6. Comparison of response of cerebral blood flow to hypoxia induced with nitrogen and with nitrous oxide when plotted against measured $\mathrm{Sa}_{\mathrm{O}_{2}}$.

flow. The absence of data at low $\mathrm{Sa}_{\mathrm{O}_{2}}$ values with nitrogen requires comment. Cardiac arrhythmias, hypertension and cardiac arrest were the sequence of events in hypoxia induced with nitrogen at low $\mathrm{Sa}_{\mathrm{O}_{2}}$. However, the use of nitrous oxide to induce hypoxia had a protective effect on dog myocardium which permitted acquisition of data at lower oxygen saturations, compared to nitrogen. The final feature of these results is the obvious fact that this methodology can be used to compare the effect of different anaesthetics on cerebral blood flow.

\section{Discussion}

Our results clearly document a linear relationship between cerebral blood flow and measured $\mathrm{Sa}_{\mathrm{O}_{2}}$ in the hypoxic range of $\mathrm{Pa}_{\mathrm{O}_{2}}$ values below $60 \mathrm{~mm} \mathrm{Hg}(7.98 \mathrm{kPa})$. We have shown that a one per cent decrease in $\mathrm{Sa}_{\mathrm{O}_{2}}$ will cause cerebral blood flow to increase 2.09 per cent with nitrous oxide hypoxia and 1.02 per cent with nitrogen induced hypoxia. Although this relationship has never before been documented, it is supported by the work of $\mathrm{Gray}^{3}$ in hypoxic dogs under methoxyflurane anaesthesia and Kogure' in hypoxic dogs under pentobarbitone anaesthesia. When cerebral blood flow was plotted against calculated $\mathrm{Sa}_{\mathrm{O}_{2}}$ on the basis of recorded $\mathrm{Pa}_{\mathrm{O}_{2}}$ values, $\mathrm{a}$ linear relationship was found. Additional supportive data were obtained from Shapiro ${ }^{5}$ in nitrogen induced hypoxia in human subjects and from Johannsson and Seiszo ${ }^{2}$ in hypoxic rats. However, in our study we measured $\mathrm{Sa}_{\mathrm{O}_{2}}$ and definitely showed for the first time the linear relationship of cerebral blood flow to $\mathrm{Sa}_{\mathrm{O}_{2}}$ in the hypoxic range of $\mathrm{Pa}_{2}$ values.

The mechanism by which hypoxia increases 
cerebral blood flow is unclear despite evidence for several possibilities. Support is divided between a local neurogenic control based on intracellular $\left[\mathrm{H}^{+}\right]$changes or a reflex neuronal control mediated by the carotid and aortic chemoreceptors. Kogure, et al. ${ }^{18}$ recently measured intracellular metabolites during short periods of hypoxia in rats. They were able to estimate increases in intracellular hydrogen ion concentration $\left(\left[\mathrm{H}^{+}\right] \mathrm{I}\right)$ with progressive hypoxia. The $\left[\mathrm{H}^{+}\right] \mathrm{I}$ increased slightly as $\mathrm{Pa}_{\mathrm{O}_{2}}$ decreased to $60 \mathrm{~mm} \mathrm{Hg}(7.98 \mathrm{kPa})$. Progressive hypoxia to $40 \mathrm{~mm} \mathrm{Hg}(5.32 \mathrm{kPa})$ produced significantly greater increases in $\left[\mathrm{H}^{+}\right] \mathrm{I}$. This suggests a metabolic control of cerebral blood flow responsive to brain tissue lactic acidosis during hypoxia and mediated by changes in $\mathrm{pH}$, according to Lassen. ${ }^{19}$ It is al so interesting to plot Kogure's $\left[\mathrm{H}^{+}\right] \mathrm{I}$ data versus $\mathrm{Sa}_{\mathrm{O}_{2}}$ instead of $\mathrm{Pa}_{\mathrm{O}_{2}}$. The result is a linear relationship between $\left[\mathrm{H}^{+}\right] \mathrm{l}$ and $\mathrm{Sa}_{\mathrm{O}_{2}}$ which by implication relates cerebral blood flow directly to $\left[\mathrm{H}^{+}\right]$l. Heistad, et al. ${ }^{20,21}$ provided added information in hypoxic dogs and monkeys which showed that carotid and aortic chemoreceptor denervation had no effect on the response of cerebral blood flow to hypoxia. In contrast, Ponte and Purves ${ }^{22}$ have concluded that carotid chemoreceptors and neurogenic mechanisms are responsible for changes in cerebral blood flow during hypoxia. Based on our results and the literature cited, it is our conclusion that there is a neurogenic control, mediated by changes in $\left[\mathrm{H}^{+}\right] \mathbf{I}$ that is responsible for the response of cerebral blood flow to hypoxia.

There are obvious advantages to viewing cerebral blood flow as a linear function of $\mathrm{Sa}_{0_{2}}$. There is an obvious ease of analysis to a linear relationship which can be expressed in equation form and analyzed by standard statistical methods. For the researcher, the relationship of cerebral blood flow and $\mathrm{Sa}_{\mathrm{O}_{2}}$ will enable comparisons to be made between anaesthetic agents, techniques, and pharmacological agents. The effects of additive factors such as $\mathrm{Pa}_{\mathrm{CO}_{2}}$ are more readily quantified with a linear relationship. For the clinician, a linear function enables the prediction of changes in cerebral blood flow with progressive hypoxia. A knowledge of changes in cerebral blood flow to be expected in hypoxia facilitates the rational use of oxygen therapy, promotes the use of osmotic diuretics, steroids or furosemide to prevent crucial changes in intracranial pressure which occur when cerebral blood flow increases, and determines the use of controlled ventilation to reduce $\mathrm{Pa}_{\mathrm{CO}_{2}}$ and so to reduce cerebral blood flow in- creased by hypoxia. Finally, it is our hope that the demonstration of a linear relationship between cerebral blood flow and $\mathrm{Sa}_{\mathrm{O}_{2}}$ will promote more rational comparisons between neurophysiological research and researchers.

\section{SUMMARY}

This study has demonstrated a linear relationship between cerebral blood flow and arterial oxygen saturation $\left(\mathrm{Sa}_{\mathrm{O}_{2}}\right.$ ) in the cerebral blood flow response in the hypoxic range of $\mathrm{Pa}_{\mathrm{O}_{2}}$ values, which we believe is documented for the first time. The cerebral blood flow increased 1.02 per cent for each percentage decrease in $\mathrm{Sa}_{\mathrm{O}_{2}}$ in hypoxia induced with nitrogen. Hypoxia induced with nitrous oxide increased cerebral blood flow at the rate of 2.09 per cent for each one per cent decrease in $\mathrm{Sa}_{\mathrm{O}_{2}}$ which was dramatically more than the increase associated with hypoxia induced with nitrogen. Increased survival rates at lower $\mathrm{Sa}_{0_{2}}$ levels suggested that nitrous oxide also exerts a protective effect on dog myocardium.

The mechanism by which hypoxia increases cerebral blood flow is unclear but the prevalent theory is one of neurogenic control which causes cerebral blood flow to increase as the int racellular hydrogen ion $\left(\left[\mathrm{H}^{+}\right] \mathrm{I}\right)$ increases in the progressive lactacidosis of hypoxia. The demonstration of a linear relationship between cerebral blood flow and $\mathrm{Sa}_{\mathrm{O}_{2}}$ will provide the statistician, the researcher and the clinician with a useful tool for the neurophysiological assessment of cerebral blood flow.

\section{RÉSUMÉ}

Cette étude démontre la relation linéaire qui existe entre le débit sanguin cérébral et la saturation artérielle oxyhémoglobinée $\left(\mathrm{Sa}_{\mathrm{O}_{2}}\right)$ lorsque le cerveau est perfusé par du sang hypoxémique. Le débit sanguin cérébral augmente de 1.02 pour cent pour chaque degré de diminution de 1 pour cent de la saturation dans l'hypoxie provoquée par l'azote. Lorsque l'hypoxie est provoquée par le protoxyde d'azote, l'augmentation du débit cérébral a été beaucoup plus dramatique et s'est produite au rythme de 2.09 pour cent pour chaque point de baisse de la saturation. L'augmentation du taux de survie pour des saturations plus basses laisse croire que le protoxyde d'azote peut protéger le myocarde du chien contre l'hypoxie.

Le mécanisme qui cause l'augmentation du débit sanguin cérébral pendant l'hypoxie est mal 
connu, la théorie la plus répandue étant celle du contrôle neurogène. Ce contrôle intervient sous l'effet de l'accumulation intracellulaire d'ions hydrogène causée par l'acidose lactique de l'hypoxie. Cette démonstration de la relation linéaire existante entre le débit sanguin cérébral et la saturation oxyhémoglobinée fournira au statisticien, au chercheur et au clinicien un outil précieux pour l'évaluation neurophysiologique du débit sanguin cérébral.

\section{ACKNOWLEDGEMENTS}

The authors are indebted to Physicians' Services Incorporated for funding for this research program. We also appreciate the technical assistance of the Anaesthesia Research Laboratory, St. Michael's Hospital, and the manuscript preparation by Miss Margaret Nettle.

\section{REFERENCES}

1. Kogure, K.. Scheingerg, P., Reinmuth, O.M., Fujishima, M., \& Busto, R. Mechanisms of cerebral vasodilation in hypoxia. J. Appl. Physiol. 29: $223(1970)$

2. Johannsson, H. \& Siesjo. B.K. Cerebral blood flow and oxygen consumption in the rat in hypoxic hypoxia. Acta Physiol. Scand. 93: 269 (1975).

3. Gray, I.G., Mitra, S.K., NisBet, H.A., Aspin, N. \& Creighton, R.E. Cerebral blood flow in hypoxemic anaesthetized dogs. Anaesth. Anai. 50: 594 (1971).

4. Shimojyo, S., Scheingerci, P., Kogure, K., \& REINMUTH, O.M. The effecis of graded hypoxia upon transient cerebral blood flow and oxygen consumption. Neurology 18: 127 (1968).

5. Shapiro, W., Wasserman, A.J. BAKER, J.P., \& PAtterson, J.C. Cerebrovascular response to acute hypocapnic and eucapnic hypoxia in normal man. J. Clin. Invest 49: 2362 (1970).

6. Lloyd, B.B., Jukes, M.G.M., \& CUNningham, D.J.C. The relationship between alveolar oxygen pressure and the respiratory response to carbon dioxide. Q. J. Exp. Physiol 43: 214 (1958).

7. Severinghaus, J.W. Hypoxic respiratory drive and its loss during chronic hypoxia. Clin. Physiol. 2: 57 (1972).
8. RebuCK, A.S., SLutsky, A.S., \& Mahutte, C.K. A mathematical expression to describe the ventilatory response to hypoxia and hypercapnia. Resp. Physiol. 31: 107 (1977).

9. Dawson, B., Michenfelder, J.D., \& Theye, R.A. Effects of ketamine on canine cerebral blood flow and metabolism: modification by prior iddministration of thiopental. Anaes. Analg. 50:443 (1971).

10. Stoyka, W.W. \& Schutz. H. Cerebral response to hypocapnia in normal and brain injured dogs. Can. Anaes. Soc. J. 2I: 205 (1974).

11. Storka, W.W. \& Schutz, H. Cerebral response to sodium nitroprusside and trimethophan controlled hypotension. Can. Anaes. Soc. J. 22: 275 (1975).

12. ANDERSON, R.E. \& Sundt, T.M. An automated cerebral blood flow analyzer: concise communication. J. Nucl. Med. 18: 728 (1977).

13. Severinghaus, J.W. Blood gas ealculator. J. Appl. Physiol, 2l: 1108 (1966).

14. Kelman, G.R. \& NUNN, J.F. Nomograms for correction of blood $\mathrm{P}_{\mathrm{O}_{2}}, \mathrm{P}_{\mathrm{Co}_{2}}, \mathrm{pH}$ and base excess for time and temperature. J. Appl. Physiol. 21: 1484 (1966).

15. THEYE, R.A. \& MiCHENFELder, J.D. The effect of nitrous oxide on canine cerebral metabolism. Anesthesiology 29: 1119 (1968).

16. Sakabe, T., Kuramoto, T., Inoue, S., \& TAKESHITA, H. Cerebial effects of nitrous oxide in the dog. Anesthesiology 48: 195 (1978).

17. Sakabe, T., Kuramoto, T., Kumagae, S., \& TAKESHITA, H. Cerebral responses to the addition of nitrous oxide to halothane in man. Br. J. Anaes. 48: $957(1976)$.

18. Kogure, K., Scheinberg, P., Utsunomiya, Y. Kishi Kawa, H., \& Busto, R. Sequential cerebral biochemical and physical events in controlled hypoxemia. Ann. Neurol. 2: 304 (1977).

19. LASSEN, N. Control of cerebrat circulation in health and disease. Circ. Res. $34: 749$ (1974).

20. Heistad, D.D., Marcus, M.L., Ehrhard, J.C., \& ABBOUD, F.M. Effect of stimulation of carotid chemoreceptors on total and regional cerebral blood flow. Circ. Res. 38: 20 (1976).

21. Heistad, D.D. \& Marcus, M.L. Evidence that neural mechanisms do not have important effects on cerebral blood flow. Circ. Res. 42: 295 (1978).

22. Ponte, J. \& Purves, M.J. The role of the carotid body chemoreceptors and carotid sinus baroreceptors in the control of cerebral biood vessels. J. Physiol. 237: 315 (1974). 